\title{
Visually Impaired Individuals in Brazil and Portugal and Learning about Drugs through a Board Game
}

\author{
Monaliza Ribeiro Mariano1, Lorita Marlena Freitag Pagliuca ${ }^{*}$, Paulo César de Almeida ${ }^{2}$, \\ Wilson Correia de Abreu $^{3}$ \\ ${ }^{1}$ Department of Nursing, Universidade Federal do Ceará, Fortaleza, Ceará, Brazil \\ ${ }^{2}$ Department of Nursing, Universidade Estadual do Ceará, Fortaleza, Ceará, Brazil \\ ${ }^{3}$ Department of Nursing, Escola Superior de Enfermagem do Porto, Porto, Portugal \\ Email: ${ }^{*}$ pagliuca@ufc.br
}

Received 6 August 2014; revised 28 August 2014; accepted 4 September 2014

Copyright (C) 2014 by authors and Scientific Research Publishing Inc.

This work is licensed under the Creative Commons Attribution International License (CC BY). http://creativecommons.org/licenses/by/4.0/

(c) (i) Open Access

\begin{abstract}
Objective: To compare the learning of visually impaired individuals after the use of the educational game "Drugs: playing it clean". Method: Quasi-experimental, comparative, before-after study. Results: The participants' mean age in Brazil was lower than in Portugal; a significant difference in information acquisition was found between the pre and post-test for the low-complexity (Brazil $p$ $=0.018$ and Portugal $p=0.002$ ), without a difference in the number of correct answers for the medium/high-complexity questions between the two countries $(p=0.655$ and $p=0.0792)$; when comparing the number of correct answers before and after the game intervention, an increase was found in Brazil and Portugal, respectively $(21.8 \%$ - 61.1\%; $11.2 \%$ - 38.9\%); a significant difference was found in the number of correct answers between the low and medium/high-complexity questions $(p=0.030)$. Conclusion: The educational game permits information access and can be used as a teaching-learning strategy.
\end{abstract}

\section{Keywords}

Learning, Visually Impaired Person, Games and Toys, Psychoactive Drugs, Nursing

\section{Introduction}

Health promotion encourages individuals' critical thinking through educational actions, so as to allow them to ${ }^{*}$ Corresponding author.

How to cite this paper: Mariano, M.R., Pagliuca, L.M.F., de Almeida, P.C. and de Abreu, W.C. (2014) Visually Impaired Individuals in Brazil and Portugal and Learning about Drugs through a Board Game. Open Journal of Nursing, 4, 677-682. 
decide on their health. To put these interventions in practice, however, intersectoral actions are needed, which presuppose articulation among the different public policy sectors [1].

Besides this articulation among sectors, competences are needed with a view to effective health promotion, such as catalyzing change, leadership, evaluation, planning, implementation, advocacy and partnership. Research, undertaken through an integrative review, indicated the main health promotion competences the professionals are developing and practicing. Catalyzing change and implementation were identified in all studies, while advocacy was the only competence not found [2]. Different professionals engage in health promotion, which should involve all people without distinction, including Visually Impaired Persons (VIP).

More than 160 million VIPs exist on the planet, 40 million of whom are blind [3]. In Brazil, VIPs are totaling 35 million, more than 500,000 (1.4\%) of whom are blind [4]. In Portugal, according to the latest census, 508,406 people over 65 years of age have sight difficulties, representing $38.7 \%$ of the people with some kind of difficulty to accomplish daily activities [5]. In Europe, the number of blind people reaches approximately 2.7 million, $7 \%$ of the population [3]. Besides the statistical data, materials produced in Braille are scarce, difficult access to information for this people, and consequently limiting your knowledge to participate in your health. In view of these data, educational resources need to be elaborated that are focused on these clients. Also, the articulation among sectors aiming for the inclusion of these people contributes to a better performance of health promotion actions.

The resources professionals use include play resources, such as educational games. These appear as a tool to modify the educational action process in care and health promotion, as the playful comprises effective learning criteria, and the knowledge produced based on this activity can be transported to reality [6]. It is considered as an educational instrument capable of contributing to the development of education and to the construction of knowledge in health [7]. Despite the knowledge acquisition, it is not sufficient by itself in health education, but constitutes the first step to produce new prevention attitudes [2].

Among the nursing tasks, health promotion permeates the care delivered to individuals and groups. Its implementation demands knowledge articulation, mobilization of human and material resources, and the consideration of all individuals. It is fundamental to acknowledge Impaired Persons (IP) as learning subjects, considering their limitations and possibilities, mainly their particularities and different learning and teaching modes [8].

In view of this context, a board game was used in Brazil and in Portugal to grant the VIPs access to information about drugs in a playful manner. "Drugs: playing it clean" is a game for pairs, consisting of a one-way board with squares of different textures, four block letters, with their respective house on the board, questions and answers, textures, pins, chips and instructions in audio, therefore accessible to the visually impaired or not. The questions addresses content drugs concept, risk and protective factors, signs and symptoms, and drug classification. In addition to questions, the game has objective answers, no simulation of risk situations, in which the player suggests a possible solution to "save" the character of the letter. These simulations are inserted into the game context deliberately in order to provide reflections and discussions between participants. The information is displayed in Braille and print. Special education experts experienced in games for the blind assessed its accessibility [9].

The comparison of post-game learning between Brazil and Portugal is justified by the acknowledgement of differences between the two cultures, as well as the fact that the drugs theme is still considered as a public health problem in both countries, causing losses for individuals and communities, despite the limited information that exists on the theme, specifically for visually impaired individuals.

In view of that context, the learning mediated by the use of the educational game "Drugs: playing it clean" was compared as an information access strategy for visually impaired individuals in Brazil and Portugal.

\section{Method}

Quasi-experimental study, which involves the manipulation of an independent variable, but without randomization or control group characteristics, as the term comparison groups is used instead of control group to refer to the group through which the results of the treatment group are assessed [10].

This study was undertaken in two associations for visually impaired people, one in the city of Fortaleza, Brazil and another in Porto, Portugal. A convenience sample was chosen, involving the use of people who are most conveniently available to participate in the study [10]. The subjects were visually impaired and blind people who complied with the inclusion criteria of reading in Braille or enlarged print. No restriction was established with regard to age, gender and education. 
The data were collected in Brazil between December 2012 and February 2013 and in Portugal between April and June 2013. In Porto, three professionals submitted the game and data collection instruments to a cultural and linguistic adaptation process, one from the mental health area and the others with experience in education and development of leisure and cultural activities with blind people.

To collect the data, two instruments were applied with regard to the pre and post-test learning. These instruments were constructed based on constructed and validated text about the theme drugs [11]. The instrument questions were classified according to the complexity level as low, medium or high, and included six questions for each.

At the start of the data collection, pairs were formed, the research objective was explained and the pre-test was applied. The players received the board game with the squares in different textures, cards in Braille and enlarged print, pins and chips. The rules of the game were available in Braille, audio or read aloud by the researcher. Next, the game started by touch and reading of the cards, without any interference by the researcher. At the end of the game, the post-test was applied.

The results were organized in tables and Wilcoxon and Mann-Whitney's statistical tests were applied to compare the proportions and mean correct answers before and after the intervention, inside and between the countries. Significance was set as $p=0.05$ and the data were processed in SPSS version 20.0, license 10101131007.

The research received approval from the Research Ethics Committee at Universidade Federal do Ceará under protocol 104/10. To develop the study in Portugal, the institution's Declaration of Authorization was considered.

\section{Results}

Thirty-six visually impaired individuals participated in the study, 18 from each country. The mean age in Portugal (49.8) was higher than in Brazil $(29.1)(\mathrm{p}<0.0001)$. As regards the education, the mean number of years of study was the same $(\mathrm{p}=0.054)$, with a slightly higher mean for Brazil (10.9 years) than for Portugal ( 9 years), according to Table 1.

When comparing the participants' correct answers before (pre-test) and after (post-test) the application of the game in the low-complexity level, the answers improved in Brazil $(\mathrm{p}=0.018)$ as well as in Portugal $(\mathrm{p}=0.002)$ (Table 2). In Brazil, before the application of the game, $27.8 \%$ of the participants correctly answered all questions, with a relevant increase after the game intervention (61.1\%). In Portugal, the difference in correct answers before and after the game was smaller: from $11.2 \%$ to $38.9 \%$. Concerning the medium/high-complexity questions, the number of correct answers was the same in Brazil $(p=0.655)$ and Portugal $(p=0.792)$.

The comparison of the mean number of correct answers between the low and medium/high-complexity questions before and after the intervention and according to the country shows that, in Brazil, before the intervention, the mean number of correct answers at the high-complexity level (0.89) was higher than at the low-complexity level $(0.72)(p=0.030)$. After the intervention, however, these means $(0.89$ and 0.86$)$ were the same $(p=0.623)$. In Portugal, before the intervention, there was an indication $(\mathrm{p}=0.054)$ that the mean number of correct answers at the low-complexity level $(0.58)$ was lower than at the medium/high-complexity level $(0.75)$; after the intervention, these means were the same $(\mathrm{p}=0.446)$.

\section{Discussion}

The educational game, as a playful intervention to learn about drugs, permitted to compare the preliminary knowledge about the theme between the participants in Brazil and Portugal, as well as the information acquisition index after the educational game intervention. Despite the inference that most people have information about drugs, this does not exclude the need for professional intervention to permit further knowledge on the losses, risk and protection factors with regard to drugs. Although alcohol abuse and illegal drugs use are considered as public health problems, their prevention and treatment has received little attention, making it relevant to focus on the factors that can contribute to the prevention of drugs use [12].

The analysis of how the game interfered in the learning about the theme showed that, in Brazil, the number of correct answers to the low-complexity questions was better than in Portugal, although both results were statistically significant. This may be related to the fact that the Portuguese subjects' mean age was higher than in Brazil, as young people are more vulnerable to risk behaviors because of the consolidation process of their personality, and also receive influence from the media, which was a powerful information source, whether in the positive or 
Table 1. Profile of the subjects in relation to age and education in Brazil and Portugal. Fortaleza, Brazil, 2014.

\begin{tabular}{ccccc}
\hline Profile & Country & Mean & Std. Deviation & p \\
\hline Age & Brazil & 29.1 & 12.9 & $<0.0001$ \\
& Portugal & 49.8 & 13.7 & 0.054 \\
\hline
\end{tabular}

Table 2. Distribution of number of correct answers in relation to total questions per complexity level in Brazil and Portugal. Fortaleza, Brazil, 2014.

\begin{tabular}{|c|c|c|c|c|c|c|c|c|}
\hline \multirow{3}{*}{ Complexity level } & \multicolumn{4}{|c|}{ Brazil } & \multicolumn{4}{|c|}{ Portugal } \\
\hline & \multicolumn{2}{|c|}{ Before } & \multicolumn{2}{|c|}{ After } & \multicolumn{2}{|c|}{ Before } & \multicolumn{2}{|c|}{ After } \\
\hline & No. & $\%$ & No. & $\%$ & No. & $\%$ & No. & $\%$ \\
\hline \multicolumn{9}{|l|}{ Low } \\
\hline $1 / 4$ & 1 & 5.6 & - & - & 4 & 22.2 & - & - \\
\hline $2 / 4$ & 5 & 27.8 & 1 & 5.6 & 6 & 33.3 & - & - \\
\hline $3 / 4$ & 7 & 38.8 & 6 & 33.3 & 6 & 33.3 & 11 & 61.1 \\
\hline $4 / 4$ & 5 & 27.8 & 11 & 61.1 & 2 & 11.2 & 7 & 38.9 \\
\hline Mean & \multicolumn{2}{|c|}{0.72} & \multicolumn{2}{|c|}{0.89} & \multicolumn{2}{|c|}{0.58} & \multicolumn{2}{|c|}{0.85} \\
\hline Median & & & & & & & & \\
\hline $\mathrm{P}$ & \multicolumn{4}{|c|}{$0.018^{(1)}$} & \multicolumn{4}{|c|}{$0.002^{(1)}$} \\
\hline \multicolumn{9}{|l|}{ Medium/High } \\
\hline $0 / 2$ & - & - & - & - & 3 & 16.7 & 2 & 11.2 \\
\hline $1 / 2$ & 4 & 22.2 & 5 & 27.8 & 3 & 16.7 & 4 & 22.2 \\
\hline $2 / 2$ & 14 & 77.8 & 13 & 72.2 & 12 & 66.6 & 12 & 66.6 \\
\hline Mean & \multicolumn{2}{|c|}{0.89} & \multicolumn{2}{|c|}{0.86} & \multicolumn{2}{|c|}{0.75} & \multicolumn{2}{|c|}{0.78} \\
\hline Median & \multicolumn{2}{|c|}{1.00} & \multicolumn{2}{|c|}{1.00} & \multicolumn{2}{|c|}{1.00} & \multicolumn{2}{|c|}{1.00} \\
\hline $\mathrm{P}$ & \multicolumn{4}{|c|}{$0.655^{(1)}$} & \multicolumn{4}{|c|}{$0.792^{(1)}$} \\
\hline $\mathrm{P}$ & \multicolumn{2}{|c|}{$0.030^{(2)}$} & \multicolumn{2}{|c|}{$0.623^{(2)}$} & \multicolumn{2}{|c|}{$0.054^{(2)}$} & \multicolumn{2}{|c|}{$0.446^{(2)}$} \\
\hline
\end{tabular}

\footnotetext{
${ }^{(1)}$ Wilcoxon's p (Before-and-after comparison in each country); ${ }^{(2)}$ Mann-Whitney's p (Comparison of complexity levels inside each country).
}

negative sense, interfering in the adolescents' behavior and education [13]. In the medium/high-complexity questions, the number of correct answers in Brazil and Portugal was the same. This fact can be attributed to the small number of questions at these levels of complexity, only two, which may have limited the analysis.

Even if the age difference was significant in the comparison between the two countries, the education level in both was the same. Hence, it can be affirmed that this variable did not influence the learning results. Despite the fact that the young adults were better informed than the older participants, this did not mean that the drug problem can be underestimated in Brazil, and even less in Portugal, where drug abuse also causeed problems. The drug problem should cause concern to health professionals as well as to people who directly deal with individuals vulnerable to the risk factors.

A prospective 12-year study showed that, among 131 crack users in São Paulo, $21 \%$ of the sample $(\mathrm{N}=27)$ had died during the follow-up period due to HIV/AIDS and drug overdose [14]. In Portugal, after a drop in the drug-related mortality in 2010 and 2011, an inversion occurred in 2012, showing 200 deaths associated with at least one illegal substance [15]. The dimension of the problems and losses for the individuals/society was evidenced, not restricted to these two countries only, as in the United States, the emergence of new synthetic drugs was observed, and the consequent increase in their use, mainly among young males [16].

The subjects in this study displayed basic knowledge about the theme before they practiced the game, and this score improved after the activity. Thus, the effectiveness of games for the teaching-learning process was highlighted, also including impaired people in some of the studies. 
The use of an educational board game stimulated the communication about sexuality and intimate relationships among young people with chronic conditions or impairments, as a promising tool to improve the communication about sexuality with young people with special health needs [17]. In that sense, different types of games are used for the purpose of entertainment, teaching and health, by health professionals from different areas, such as nursing, medicine, health care, physical exercise, and are valid as an intervention strategy to benefit the general population [18].

This study indicates play as a teaching-learning possibility, in accordance with other studies, specifically for visually impaired people. The data allow both health and education professionals to verify that they can use this resource not only for fun, distraction, play for the sake of playing, but as a pedagogical strategy, aimed at: imposing limits and rules, developing self-confidence, enhancing the concentration and logical reasoning, stimulating creativity and affection, conducting the construction of knowledge and significant learning [19].

\section{Conclusions}

After the application of the educational game, in Brazil as well as in Portugal, an improvement was perceived in the number of correct answers related to the theme. In Brazil, the number of correct answers to all questions increased from $27.8 \%$ to $61.1 \%$; in Portugal, the percentage rose from $11.2 \%$ to $38.9 \%$.

The educational game intervention positively influenced the Brazilian and Portuguese visually impaired individuals' information acquisition, even if they already had basic knowledge on the theme. A significant difference was found for the low-complexity questions before and after the application of the game in the two countries.

The small number of participants and also the inequitable distribution of questions by level of complexity may have influenced the analysis, considered limitation of the study.

Forward to the results, the use of the game to educational intervention is considered appropriate to report on psychoactive substances, in Brazilian culture and Portuguese, considering that drug abuse is a public health problem in both countries and that the blind population has limited access to information.

\section{References}

[1] Pintor, N.A.M., Llerena Jr., J.C. and Costa, V.A. (2012) Educação e saúde: Um diálogo necessário às políticas de atenção integral para pessoas com deficiência. Revista de Educação Especial, 25, 203-216. http://dx.doi.org/10.5902/4935

[2] Mariano, M.R., Pinheiro, A.K.B., Aquino, P.S., Ximenes, L.B. and Pagliuca, L.M.F. (2013) Jogo educativo na promoção da saúde de adolescentes: Revisão integrativa. Revista Eletrônica de Enfermagem, 15, 265-273. http://dx.doi.org/10.5216/ree.v15i1.17814

[3] World Health Organization (2014) Visual Impairment and Blindness. http://www.who.int/mediacentre/factsheets/fs282/en/

[4] Instituto Brasileiro de Geografia e Estatística (IBGE) (2014) Censo demográfico 2010: Características gerais da população. http://www.ibge.gov.br/home/estatistica/populacao/censo2010/populacao/censo2010 populacao.pdf

[5] Instituto Nacional de Estatística (2014) Bem-vindo aos Censos 2011. A maior fonte de informação nacional sobre a população, a família e a habitação. http://censos.ine.pt/xportal/xmain?xpid=CENSOS\&xpgid=censos2011_apresentacao

[6] Coscrato, G., Pina, J.C. and Mello, D.F. (2010) Utilização de atividades lúdicas na educação em saúde: Uma revisão integrativa da literatura. Acta Paulista de Enfermagem, 23, 257-263. http://dx.doi.org/10.1590/S0103-21002010000200017

[7] Yonekura, T. and Soares, C.B. (2010) The Educative Game as a Sensitization Strategy for the Collection of Data with Adolescents. Revista Latino-Americana de Enfermagem, 18, 968-974. http://dx.doi.org/10.1590/S0104-11692010000500018

[8] Carneiro, M.S.C. (2012) Reflexões sobre a avaliação da aprendizagem de alunos da modalidade Educação Especial na Educação Básica. Revista Educação Especial, 25, 513-530. http://dx.doi.org/10.5902/1984686X7190

[9] Mariano, M.R., Rebouças, C.B.A. and Pagliuca, L.M.F. (2013) Construção e avaliação de jogo educativo sobre drogas para cegos. Revista de Escola de Enfermagem da USP, 47, 930-936. http://dx.doi.org/10.1590/S0080-623420130000400022

[10] Polit, D.F. and Beck, C.T. (2011) Livro-Fundamentos de pesquisa em enfermagem: avaliação de evidências para a prática da enfermagem. 7th Edition, Artmed, Porto Alegre. 
[11] Cezario, K.G. and Pagliuca, L.M.F. (2007) Tecnologia assistiva em saúde para cegos: Enfoque na prevenção de drogas. Escola Anna Nery, 11, 677-681. http://dx.doi.org/10.1590/S1414-81452007000400019

[12] Dennhardt, A.A. and Murphy, J.G. (2013) Prevention and Treatment of College Student Drug Use: A Review of the Literature. Addictive Behaviors, 38, 2607-2618. http://dx.doi.org/10.1016/j.addbeh.2013.06.006

[13] Zeitoune, R.C.G., Ferreira, V.S., da Silveira, H.S., Domingos, A.M. and Maia, A.C. (2012) Knowledge of Teenagers about Licit and Illicit Drugs: A Contribution to Community Nursing. Escola Anna Nery, 16, 57-63. http://dx.doi.org/10.1590/S1414-81452012000100008

[14] Dias, A.C., Araújo, M.R., Dunn, J., Sesso, R.C., de Castro, V. and Laranjeira, R. (2011) Mortality Rate among Crack/Cocaine-Dependent Patients: A 12-Year Prospective Cohort Study Conducted in Brazil. Journal of Substance Abuse Treatment, 41, 273-278. http://dx.doi.org/10.1016/j.jsat.2011.03.008

[15] Antidrogas (2014) Cannabis, cocaína e ecstasy drogas mais consumidas em Portugal em 2012. Publicado a 17 DEZ 13 às $17: 15$. http://www.antidrogas.com.br/mostraartigo.php?c=4093\&msg=Cannabis, $\% 20$ coca $\%$ EDna $\% 20 \mathrm{e} 20$ ecstasy $\% 20$ foram $\%$ 20as $\% 20$ drogas $\% 20$ mais $\% 20$ consumidas $\% 20 \mathrm{em} \% 20$ Portugal $\% 20 \mathrm{em} \% 202012$

[16] Maxwell, J.C. (2014) Psychoactive Substances-Some New, Some Old: A Scan of the Situation in the U.S. Drug and Alcohol Dependence, 134, 71-77. http://dx.doi.org/10.1016/j.drugalcdep.2013.09.011

[17] van der Stege, H.A., Staa, A.V., Hilberink, S.R. and Visser, A. (2010) Using the New Board Game SeCZ TaLK to Stimulate the Communication on Sexual Health for Adolescents with Chronic Conditions. Patient Education and Counseling, 81, 324-331. http://dx.doi.org/10.1016/j.pec.2010.09.011

[18] Wattanasoontorn, V., Boada, I., García, R. and Sbert, M. (2013) Serious Games for Health. Entertainment Computing, 4, 231-247. http://dx.doi.org/10.1016/j.entcom.2013.09.002

[19] Silva, K.C.O. and Levandoski, A.A. (2014) O Jogo como Estratégia no Processo Ensino-Aprendizagem de Matemática

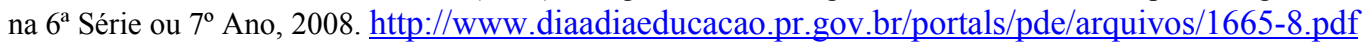


Scientific Research Publishing (SCIRP) is one of the largest Open Access journal publishers. It is currently publishing more than 200 open access, online, peer-reviewed journals covering a wide range of academic disciplines. SCIRP serves the worldwide academic communities and contributes to the progress and application of science with its publication.

Other selected journals from SCIRP are listed as below. Submit your manuscript to us via either submit@scirp.org or Online Submission Portal.
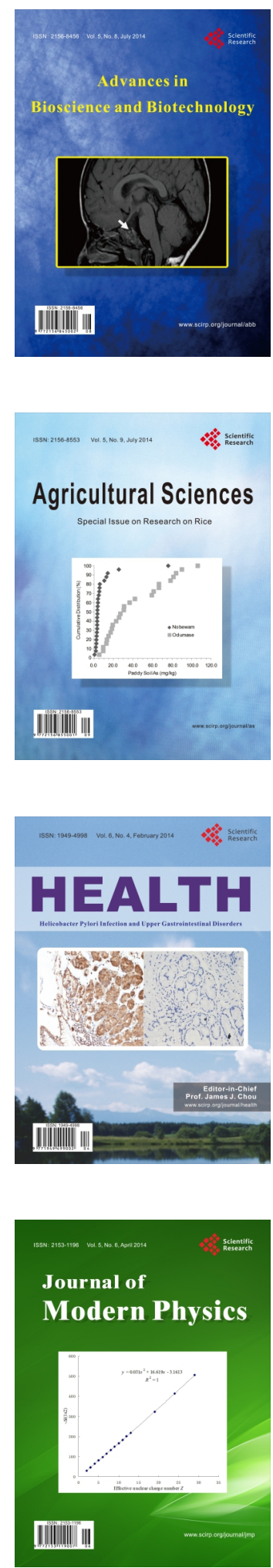
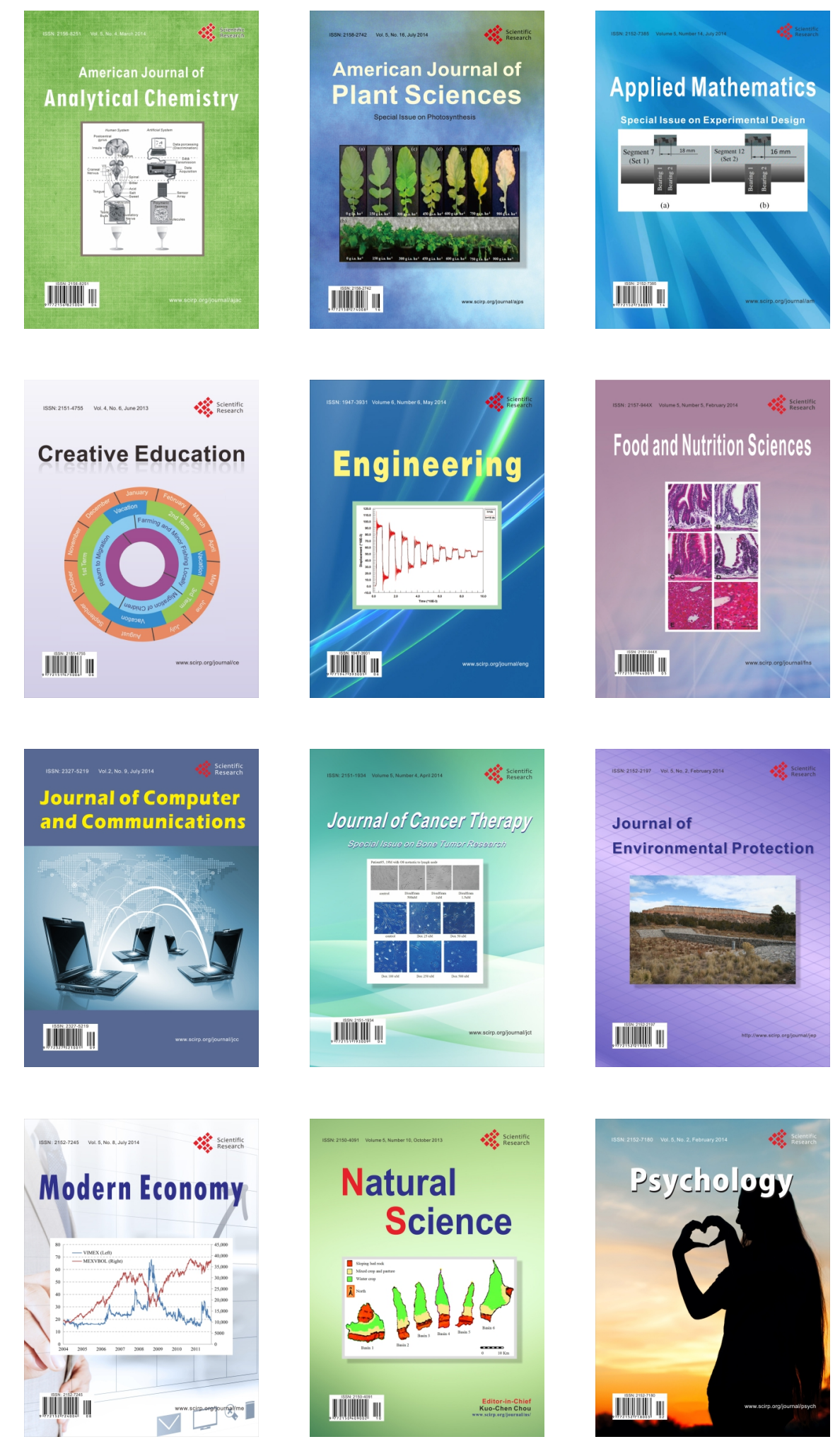